\title{
ANÁLISE DO PERIGO DE INUNDAÇÃO NA BACIA HIDROGRÁFICA DO RIO TAPACURÁ -PE
}

\author{
Marcela RicardoBezerra deMiranda ${ }^{(a)}$,Manuella Vieira Barbosa Neto ${ }^{(b)}$, Edmário Marquesde \\ Menezes Júnior ${ }^{(\mathrm{c})}$,Osvaldo Girão ${ }^{(\mathrm{d})}$ \\ ${ }^{(a)}$ docente, IFPE/DASS/CGEO,marcelorbmiranda@gmail.com \\ (b) docente, IFPE/DASS/CGEO, manuellaneto@ recife.ifpe.edu.br \\ (c) doutorando, UFPE/PPGEO, edmario.menezes@ @otmail.com \\ (d) docente, UFPE/DCG/PPGEO, osgirao@gmail.com
}

\section{EIXO: BACIAS HIDROGRÁFICAS E RECURSOS HÍDRICOS: ANÁLISE, PLANEJAMENTO E GESTÃO}

\begin{abstract}
Resumo
O fenômeno de inundação tem sido algo recorrente no meio urbano brasileiro nas últimas décadas, causando graves prejuízos materiais e, eventualmente, perdas de vidas humanas. A cidade de Vitória de Santo Antão, localizada na Zona da Mata de Pernambuco tem registrado muitos eventos ao longo de sua história, o ano de 2005 marcoua principal inundação ocorrida na história recente, além de outrasocorrências em 2010 e 2011. O objetivo deste trabalho foi verificar quais áreas da BHRT apresenta suscetibilidade à ocorrência deinundação.Foi utilizada uma metodologia que analisa alguns aspectos morfométricosda bacia hidrográfica como a declividade do terreno e da densidade de drenagem, obtendo-se o Mapa de Perigo de Inundação. Verificou-se que o local com maior incidência de inundação é o médio curso da bacia, exatamente onde se localiza o distrito sede de Vitória de Santo Antão confirmando as áreas que registraram inundações nos últimos anos.
\end{abstract}

Palavras Chave: Perigo de Inundação; Densidade de drenagem; Vitória de Santo Antão.

\section{1 - INTRODUÇÃO}

Atualmente, muito se fala a respeito de desastres naturais e, a cada ano são milhões de dólares que se perdem em função de terremotos, incêndios, atividades vulcânicas, tsunamis, secas e inundações. Sabe-se que esses eventos naturais ocorrem mesmo sem a intervenção direta da humanidade, no entanto, devido às transformações do espaço natural a partir das expansivas e intensivas formas de usos e ocupações da terra, está havendo uma potencialização dos efeitos dos mesmos.

Compreender os mecanismos que influenciam esses eventos seja eles de ordem natural ou antrópica é crucial, pois, os cenários que estão sendo construídos para o futuro do planeta, estão embasados na ocorrência de mais catástrofes, e consequentemente, maiores prejuízos e riscos de perdas humanas.

A área foco deste estudo na Bacia Hidrográfica do Rio Tapacurá, doravante referenciada pela sigla BHRT, em Pernambuco,tem registrado recorrentes episódios de inundações. De acordo com Castro (2003); Tucci (2005) e Tominagaet al. (2009) o evento de inundaçãoé caracterizado pelo transbordamento das águas de um curso d'água atingindo a planície de inundação ou área de várzea. E 
XVII Simpósio Brasileiro

de Geografia Fisica Aplicada

I Congresso Nacional

de Geografia Física
OS DESAFIOS DA GEOGRAFIA FÍSICA NA FRONTEIRA DO CONHECIMENTO

Instituto de Geociências - Unicamp

Campinas - SP

28 de Junho à 02 de Julho de 2017

as enchentes seriam definidas pela elevação do nível d'água no canal de drenagem devido ao aumento da vazão, atingindo a cota máxima do canal, porém, sem extravasar.

O município de Vitória de Santo Antão detém a maior área dentro dos limites da BHRT, estando localizado no médio curso, sendo o distrito sedecortadonoseu perímetro urbano pelas águas do rio Tapacurá. Esse município tem enfrentado graves eventos naturais com inundaçõesao longo de sua história e estão cada vez mais intensas e frequentes. Nos últimos anos aconteceram três grandes enchentes, 2005 registrou a maior catástrofe natural do município, além de ocorrências também nos anos de 2010 e 2011.

Considerando tantos eventos de inundaçãosurge a questão se o município de Vitória de Santo Antão apresenta perigo deinundação?Para responder essa questão e conhecer as causas, foram estudados vários autores que tratam sobre o tema como: Tucci (2005), Alves et. al. (2012) e Andrade et. al. (2014), além do estabelecimento de algumas metodologias para analisar elementos que são considerados importantes como os aspectos morfométrico e morfodinâmico da bacia em questão.

Braga (2001) analisou as condições morfométricas da BHRTe afirma não haver condições naturais para ocorrência de inundações,no entanto, essas ocorrem. Sendo importante destacar que a área encontra-se no contexto geoambiental das superfícies retrabalhadas da zona da mata pernambucana, não sendo, portanto, uma planície de inundação. Nesse sentido, essa pesquisa tem por objetivo verificar se a BHRT apresenta perigo de inundação baseando-se na análise de alguns aspectos morfométricos.A resposta foi obtida conforme o uso de álgebra de mapas adotadas na metodologia desenvolvida por Alves et. al (2012) que analisa a declividade, a densidade de drenagem e a proximidade entre canais, resultando em um mapa de Perigo de Inundação.

\subsection{A influência das características morfodinâmica e geoestrutural sobre o processo de inundação}

É importante estabelecer que a análise de uma área para reconhecer as reais condições de perigo e potencial vulnerabilidade perpassa pelo reconhecimento das dinâmicas dos fatores naturais e, considerar não apenas o presente e nem o futuro, mas principalmente, analisar o passado desse local.

A demanda sobre estudos de bacias hidrográficas estabelece necessariamente contextos que norteie temas que abordem, sobretudo, a questão morfodinâmica e geoestrutural da localidade de uma bacia, no entanto, também é importante dedicar atenção às transformações antrópicas que elas estão sujeitas (MACHADO e TORRES, 2012). É sabido que na dinâmica natural muito se transforma, quando consideramos os processos de mudança do meio, mas são transformações extremamente lentas se comparado àquelas impetradas pela ação humana. 
XVII Simpósio Brasileiro

de Geografia Física Aplicada

I Congresso Nacional

de Geografia Física
OS DESAFIOS DA GEOGRAFIA FÍSICA NA FRONTEIRA DO CONHECIMENTO

Instituto de Geociências - Unicamp

Campinas - SP

28 de Junho à 02 de Julho de 2017

Os resultados dessas mudanças provocadas por ações antrópicas, ao interferirem na dinâmica dos fluxos e matérias de um sistema fluvial ou mesmo ao ocuparem seus espaços, fez com que a própria população impetrante de mudanças se torne vítimas de eventos fluviais potencializados.

No estudo das características que influenciam na análise morfodinâmica é preciso considerar que aspecto físico de uma bacia hidrográfica é adquirida através de mapas, fotografias aéreas e imagens de satélite, como por exemplo: área, comprimento, declividade e cobertura do solo, que podem ser expressos diretamente ou, por índices que relacionam os dados obtidos (PORTO, 2006).

Ainda segundo Porto (2006), as bacias hidrográficas têm uma grande variedade de formas, que refletem o comportamento hidrológico da bacia, podendo se apresentar com formas circulares, alongadas ou ramificadas. Em uma bacia circular, por exemplo, toda a água escoada tende a alcançar a saída da bacia ao mesmo tempo,favorecendo a ocorrência de inundação.

Uma bacia alongada, tendo a saída na ponta do maior eixo e, mesmo sendo a área igual à de uma bacia circular, o escoamento será mais distribuído no tempo, produzindo, portanto, uma menor capacidade de inundação. (NAGHETTINI, 2000).

As bacias do tipo radiais ou ramificadas são formadas por conjuntos de sub-bacias alongadas que convergem para um mesmo curso principal. Nesse caso, uma chuva uniforme em toda a bacia, origina cheias nas sub-bacias, que vão se somar, mas não simultaneamente, no curso principal. Portanto, a cheia crescerá, estacionará, e gradualmente diminuirá na medida em que forem se fazendo sentir as condições das diferentes sub-bacias (NAGHETTINI, 2000).

Segundo Porto (2006) o tempo de deslocamento do escoamento em uma bacia é um dado de extrema importância para estudos da drenagem, sendo ele o indicador das características do escoamento de uma precipitação.

A declividade de uma bacia constitui o mais importante parâmetro para identificar as bacias ou partes delas, mais vulneráveis à atuação de processos erosivos e de enchentes e inundações (MACHADO e TORRES, 2012). A declividade controla em grande medida a velocidade com que se dá o escoamento superficial, afetando assim a maior ou menor infiltração da água, oportunizando picos de inundação ou a maior suscetibilidade de erosão dos solos.

Os rios são os principais agentes geomorfológicos que atuam na superfície da Terra. À medida que erodem o substrato rochoso e transportam e depositam areia, cascalho e lama, todos os rios, desde os pequenos riachos até os mais caudalosos, são proeminentes escultores da paisagem (PRESS et al, 2008).Importante é considerar a atuação da água da chuva que não se infiltra no solo e escoa superficialmente, sendo lenta e gradualmente coletada pelos rios e lagos. A natureza do solo e a capacidade de infiltração ou consequente impermeabilização são fatores determinantes para a compreensão das eventuais enchentes, comuns nos centros urbanos (POPP, 2010).

Destaca-se também o estudo do solo a sua estruturação e composição, sendo ela determinante para a compreensão da cobertura vegetal. O significado ecológico dos solos está no fato 
dele interferirna distribuição dos grupos de plantas, em virtude de suas composições nutricionais e química, influenciando para uma maior ou menor capacidade do desenvolvimento vegetativo.ROSS (1996).

\section{2 - MATERIALE MÉTODOS}

\section{1 Áreada BHRT}

A BHRTpossui uma área de 471,33 $\mathrm{Km}^{2}$ estando localizada entre as mesorregiões da Zona da Mata e do Agreste Pernambucano e é uma sub-bacia da bacia hidrográfica do Rio Capibaribe. Ela abrange seis municípios pernambucanos: Vitória de Santo Antão, Pombos, São Lourenço da Mata, Gravatá, Moreno e Chã Grande(BRAGA, 2001). Os dois primeiros são os mais representativos com $38,6 \%$ e $31,2 \%$ de área ocupada pela bacia, respectivamente, e os únicos com as sedes distritais cortada pelo rio Tapacurá(DUARTE, 2009).
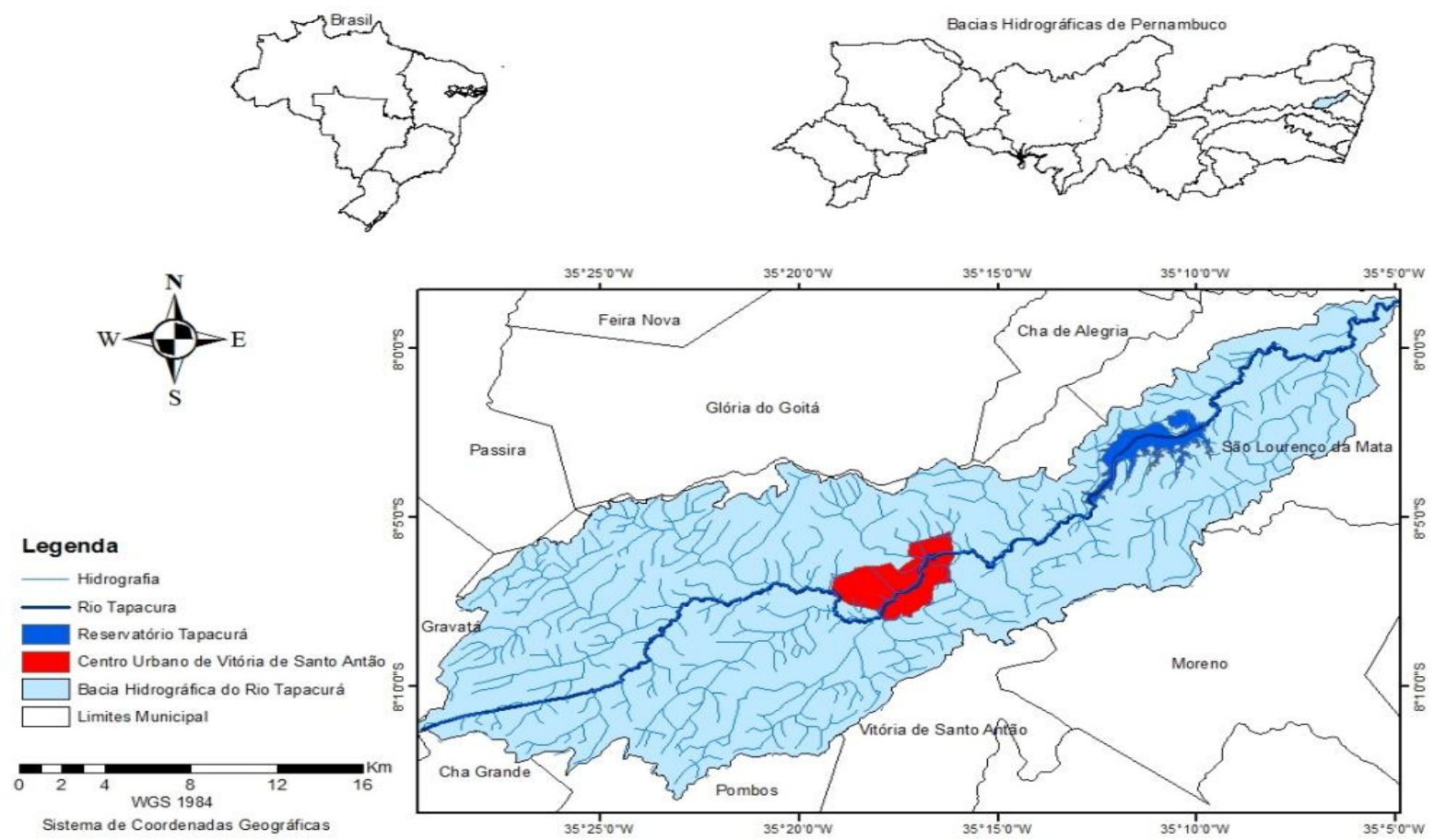

Figura 01: Localização da Bacia Hidrográfica do Rio Tapacurá em relação ao estado de Pernambuco

Amorfoestrutura da bacia se caracteriza predominantemente pela presença de rochas do complexo gnáissico-magmátito indiscriminado formadas no paleoproterozóico, ocorrendo feições intensamente retrabalhadas, principalmente, nas direções NW a SW, contribuindo pra estabelecer uma área captadora e geradora de maior fluxo de escoamento das águas superficiais(DUARTE, 2009). 
XVII Simpósio Brasileiro

de Geografia Física Aplicada

I Congresso Nacional

de Geografia Física
OS DESAFIOS DA GEOGRAFIA FÍSICA NA FRONTEIRA DO CONHECIMENTO

Instituto de Geociências - Unicamp

Campinas - SP

28 de Junho à 02 de Julho de 2017

O solo se caracteriza, principalmente, pela presença dos Argissolos vermelho-amarelos e Argissolos amarelos (DUARTE, 2009).Ainda conforme a autora essa região apresenta uma deficiência da capacidade de infiltração dos solos, motivados pela presença de um horizonte B subsuperficial com significativo teor de argila tornando-o um fator redutor para a infiltração. Já no trecho dos planaltos rebaixados encontramos o Latossolo nos topos planos, sendo profundos e bem drenados; nas vertentes íngremes temos o Argissolo, sendo pouco a medianamente profundo e bem drenado, e também oGleissolo de Várzea nos fundos de vales estreitos, com solos orgânicos e encharcados (CPRM, 2005).Esse solo mineral e hidromórfico formado devido à influência do excesso de umidade permanente ou temporário caracterizam-se por ser mal a muito mal drenado.

Quanto ao uso e ocupação do solo a BHRT tem uma grande área antropizada resultante, principalmente, do cultivo extensivo canavieiro intercalado por áreas de pastoreio e de agricultura familiar em pequenas propriedades.

\subsection{Aspectos Metodológicos}

Para delimitação da bacia foi realizada uma avaliação cartográfica com o auxílio de cartas topográficas, da Superintendência de Desenvolvimento do Nordeste (SUDENE), na escala de 1:25.000. Estas cartas possuíam elementos topográficos capazes de identificar os limites da bacia a serem considerados na análise, e permitiram a criação inicial de um arquivo cartográfico operacional.

Foram confeccionados produtos cartográficos como ferramentas indispensáveis na representação espacial, visando compreender os processos hidrodinâmico, assim como, as características físicas e comportamentais através do geoprocessamento com dados Topodata.

A escolha do modelo de construção do Mapa de Perigo de Inundação a partir da metodologia desenvolvida por Alves et al. (2012) se estabeleceu devido esse utilizar um processo por nós considerados simples e apresentar parâmetros de fácil execução, além de resultados objetivos e confiáveis, para a análise do aspecto hidrológico e morfodinâmico da bacia em questão.

O modelo concebido por Alves et al. (2012) leva em conta que:

1 - áreas com fortes declividades possuem maior probabilidade de inundação rápida do que áreas planas;

2 - Canais com maior número de contribuintes (magnitude Shreve) possuem maior potencial de inundação;

3 - Canais próximos possuem maior possibilidade de potencializar os efeitos de suas inundações, deste modo, áreas com maior densidade de canais por $\mathrm{km}^{2}$ são mais suscetíveis a inundações de maiores proporções. 
XVII Simpósio Brasileiro

de Geografia Física Aplicada

I Congresso Nacional

de Geografia Física
OS DESAFIOS DA GEOGRAFIA FÍSICA NA FRONTEIRA DO CONHECIMENTO

Instituto de Geociências - Unicamp

Campinas - SP

28 de Junho à 02 de Julho de 2017

Conhecendo esse perfil metodológico e utilizando os dados obtidos na confecção dos mapas de atributos naturais da bacia foi possível chegar ao estabelecimento da área de Instabilidade morfodinâmica vulnerável à inundação na BHRT.

Para produzir o mapa de perigo de inundação, inicialmente, foi compilada a base de dados temáticos sobre a bacia: limites da bacia, dados de elevação e declividade, estes dois últimos obtidos do projeto TOPODATA (VALERIANO, 2008).

Os dados de elevação e declividade foram recortados com base nos limites da bacia. Em seguida, a partir dos dados altimétrico, foi extraída a rede de drenagem com valor de fluxo acumulado superior a 100 células, produzindo uma malha de canais bastante densa, refletindo assim as áreas mais suscetíveis de ocorrência de fluxo canalizado (ALVES et. al., 2012).

A partir disso foi gerado um arquivo com a magnitude (Shreve) da rede de drenagem, onde a magnitude de um canal é definida pelo número de contribuintes que estão à montante. Este arquivo, foi convertido para o formato vetorial, em seguida foi submetido a um estimador de densidade Kernel, que superestima valores de densidade de drenagem quanto maior for a proximidade entre os canais, representando o fato de o transbordamento de canais próximos poderem ocupar áreas mais rápido do que canais que estejam mais distantes (SILVERMAN, 1986). Por fim, o arquivo foi recortado no formato da bacia e reclassificado em 5 classes.

$\mathrm{O}$ arquivo de drenagem comum também foi convertido para o formato vetorial, mas foi submetido a um estimador de densidade linhas que, ao contrário do estimador Kernel, não superestima valores de densidade de drenagem com base na proximidade entre os canais. Por fim, o arquivo foi recortado no formato da bacia e reclassificado em 5 classes.

Os valores de declividade seguiram as classes propostas pela EMBRAPA e foram reclassificados do mais plano (1) para o mais inclinado (6) Os três arquivos reclassificados (declividade, densidade de canais e densidade da magnitude Shreve) foram submetidos a uma adição simples a partir de um operador algébrico de mapas, resultando num modelo do perigo de inundação, que apresenta distribuição dos pesos em três classes, originada com subsídio do software Arcgis 9.3. Neste produto constam as unidades de instabilidade até estabilidade, seguindo os graus de vulnerabilidade Baixo, Médio e Alto.

\section{3 - RESULTADOS E DISCUSSÕES}

É importante considerar que não é tão e somente as altas pluviosidades que provocam as inundações em determinadas áreas. É preciso considerar o argumento de Vilella e Mattos (1975) quando afirmam que existe uma correspondência entre as características físicas de uma bacia e o regime hidrológico, pois através de relações e comparações entre esses dois elementos pode-se 
XVII Simpósio Brasileiro

de Geografia Física Aplicada

I Congresso Nacional

de Geografia Física
OS DESAFIOS DA GEOGRAFIA FÍSICA NA FRONTEIRA DO CONHECIMENTO

Instituto de Geociências - Unicamp

Campinas - SP

28 de Junho à 02 de Julho de 2017

determinar, indiretamente, valores hidrológicos que apontem se a área é vulnerável a perigo de inundações, por motivações morfológicas.

Analisando as variáveis morfométricas foi possível compreender a dinâmica de escoamento no interior da bacia e destacar que as maiores áreas suscetíveis a inundações estão localizadas no baixo curso. Mas, é possível distinguir áreas com ocorrência de inundações de curta e média duração e média velocidade de escoamento, na região do médio curso, situação corroborada no Mapa de Perigo de Inundação.

Ao considerar os resultados dos dados relativos às questões de forma e drenagem da bacia, foram utilizados os valores de referência para alguns dos pontos com o propósito de compará-los com os resultados e foi verificado que: conforme os dados apontam: o Coeficiente de Compacidade de 2,02obtidos de Duarte (2009), a BHRT não seria uma bacia sujeita à inundação, em sua condição natural, pois, conforme Andrade et al. (2014) os índices capazes de apontar uma propensão natural de inundação seria entre 1,00 até 1,25 ou eventualmente até 1,50.

Quando consideramos o Índice de Forma, o resultado produzido por Duarte (2009)foi de 0,18 ,o que resultaria no fato de que a bacia em questão também não seria sujeita a inundações, em seu estado natural, isso, conforme os valores de referência adotados de Andrade et al. (2014) que apontam como fator de forma determinante para a propensão de inundação resultados entre 1,00 até 0,75 e que resultados menor que 0,50 seriam caracterizados como não sujeitos a inundações. Segundo Machado e Torres (2012), esse índice relaciona a forma da bacia com um retângulo. No caso de uma bacia estreita e longa, a possibilidade de ocorrência de chuvas intensas cobrindo, ao mesmo tempo, toda sua extensão, é menor do que em bacias largas e curtas.

No entanto, essa situação resulta do índice obtido para toda a bacia, mas pode apresentar variabilidade interna quando analisadosalguns trechos separadamente. Sabe-se que o médio curso da BHRT tem apresentado constantes inundações e essas, seriam resultantes da alta densidade de drenagem nesse trecho, e episódios de precipitações extremas, além das transformações antrópicas na área.

Considerando os dados de densidade de drenagem obtidos pelo método gerado de Horton (1945) apud Silva et al. (2009), observou-se que os resultados da BHRT apresentam valores entre 73,30 a 659,74 , portanto, caracterizando a bacia com alta densidade de drenagem, elemento que permite compreender as ocorrências de inundações constantes na área. Esse dado corrobora com o dados obtidosno mapa de Perigo de Inundação da Bacia, que apresentou exatamente sobre o médio curso uma área de grande densidade de drenagem que contribuíam para o escoamento das águas correspondendocom o trecho urbano do município de Vitória de Santo Antão.

\subsection{O Perigo de Inundação na BHRT}




\section{OS DESAFIOS DA GEOGRAFIA FÍSICA NA FRONTEIRA DO CONHECIMENTO Instituto de Geociências - Unicamp Campinas - SP 28 de Junho à 02 de Julho de 2017}

Averificação do perigo de inundação da bacia no médio curso se deve a um conjunto de fatores associados, como: os geológicos, dos solos, da ocupação do solo, aliada a alta pluviosidade que incide eventualmente sobre ela, e sobretudo, ao padrão de drenagem local.

Ao analisar a morfoestrutura da bacia nesse trecho ela se caracteriza pela presença de rochas e solo que apresenta uma deficiência na capacidade de infiltraçãoda água, resultando em um aumento da dinâmica de escoamento superficial que promove grande acumulação durante os eventos de grande energia no local. Também merece destaque a topografia de NW - SW da bacia que devido ocorrência de grande declividade acaba contribuindo pra estabelecer uma área geradora de maior fluxo de escoamento das águas nesse trecho demédio curso do Rio Tapacurá.

É preciso esclarecer que ao analisar os dados de Alto Perigo de Inundação na BHRT obtido pelo uso de metodologia que considera alguns aspectos morfométricos, existe uma grande área destacadaa jusante no mapa, e essa representa a Barragem de Tapacurá. É certo que a ocorrência de alto perigo à jusante seria um fator natural, mas devido o represamento das águas nesse trecho da bacia comprometeu a análise, uma vez que ela provocou alterações significativas da dinâmica das águas a partir desse local. 
XVII Simpósio Brasileiro de Geografia Fisica Aplicada

I Congresso Nacional de Geografia Física

\section{OS DESAFIOS DA GEOGRAFIA FÍSICA NA FRONTEIRA DO CONHECIMENTO Instituto de Geociências - Unicamp Campinas - SP \\ 28 de Junho à 02 de Julho de 2017}

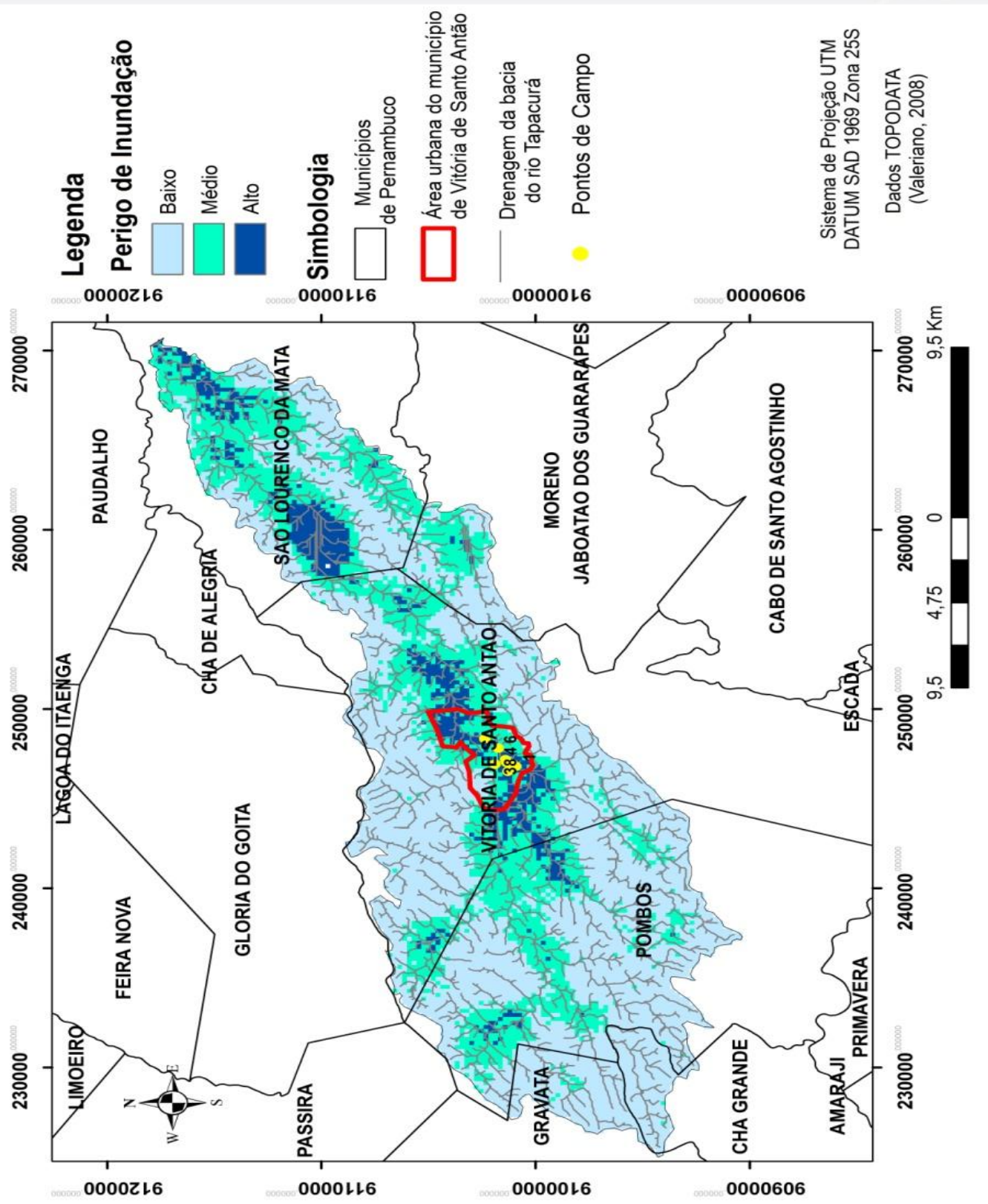

Figura 02 - Mapa de Perigo de Inundação da Bacia Hidrográfica do Rio Tapacurá

É possível comparar essas áreas de perigo com as áreas que regularmente vem registrando inundações, e verificou-se que há correspondência dos principais locais com os episódios ocorridos em 2005, 2010 e 2011.

De maneira a permitir a visualização da comparação das áreas de Perigo de Inundação do mapa, foi feito um recorte na altura do distrito sede do município de Vitória de Santo Antão (figura 3) e marcado as áreas que registraramgrandes episódios de inundação na última década (figuras de 4 até 7).Assim, foi possível confirmar os resultados obtidos no mapa e que esse trecho do médio curso do Rio Tapacurá apresenta alto perigo de inundação. 


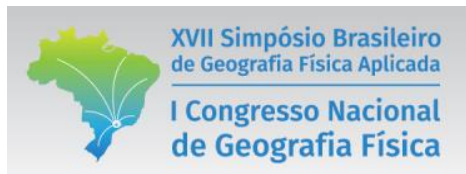
OS DESAFIOS DA GEOGRAFIA FÍSICA NA FRONTEIRA DO CONHECIMENTO Instituto de Geociências - Unicamp Campinas - SP
28 de Junho à 02 de Julho de 2017

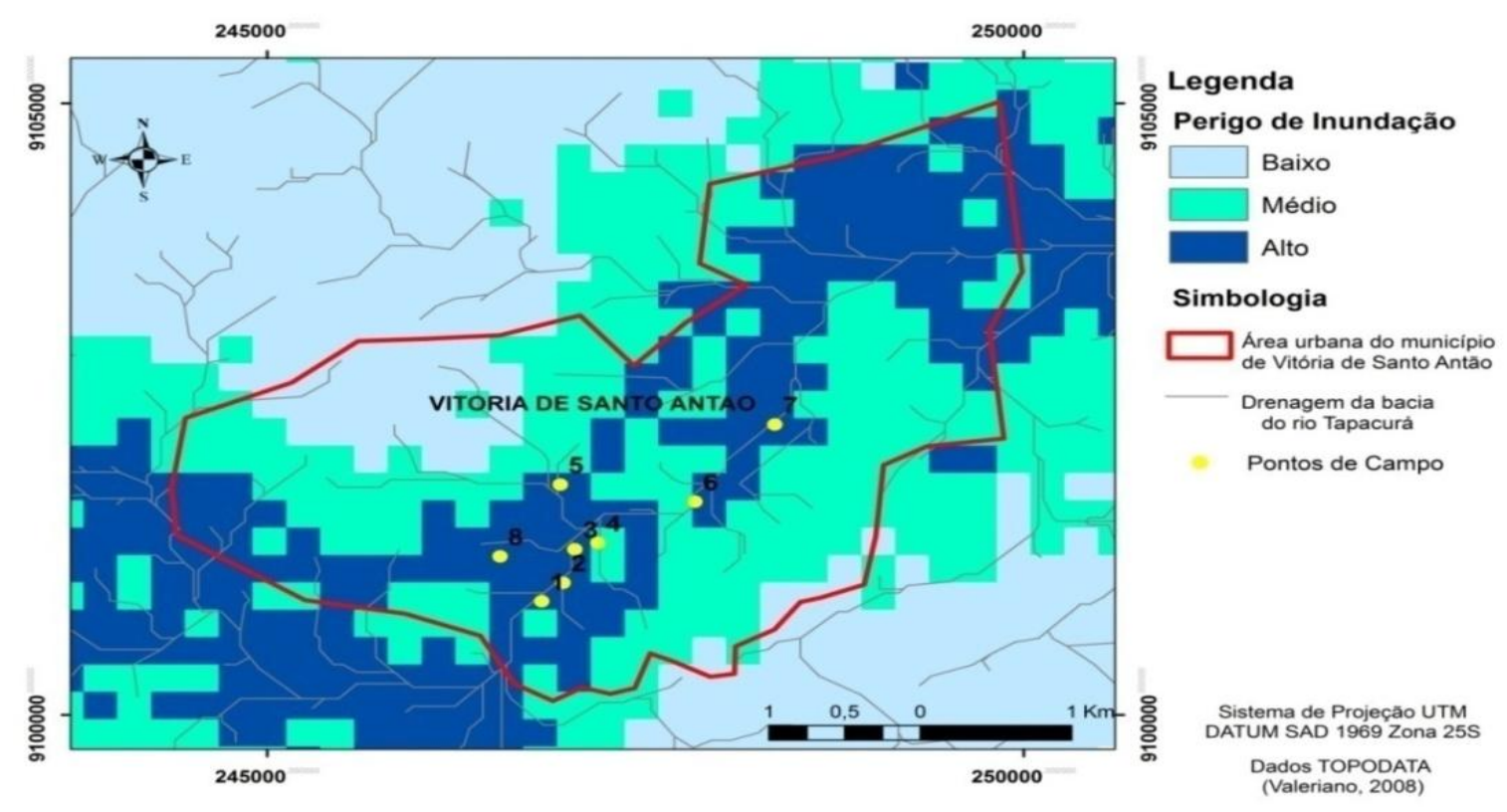

Figura 03 - Recorte da BHRT com comparação de áreas que registraram inundação no município de Vitória de Santo Antão.

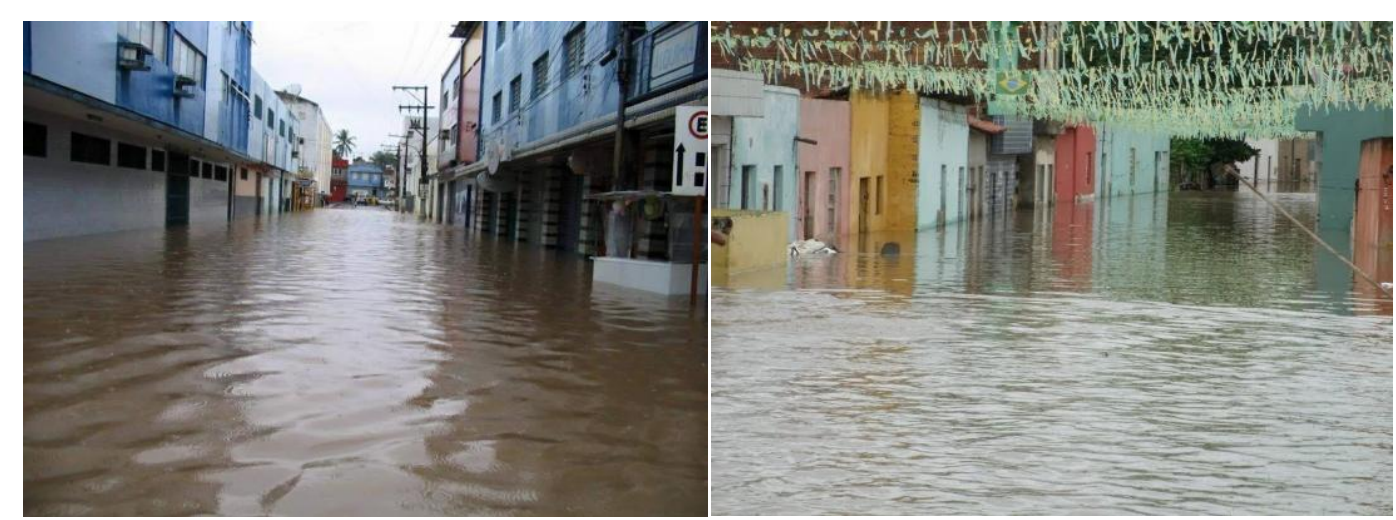

Figura 04 - inundação Av. XV de novembro. Ponto 5 Fonte: Jornal a Verdade, 2005.
Figura 05 - inundação na Rua da Madeira. Ponto 6 Fonte: A voz da Vitoria, 2010.

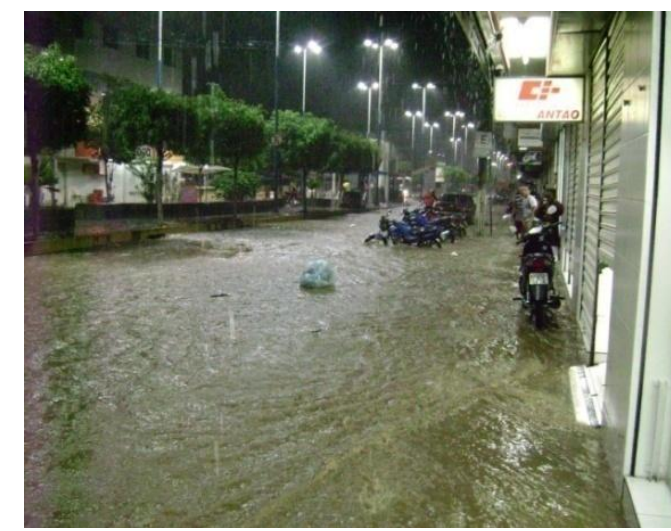

Figura 06 - inundação Av. Mariana Amália. Ponto 3 Fonte: A voz da Vitória, 2011.

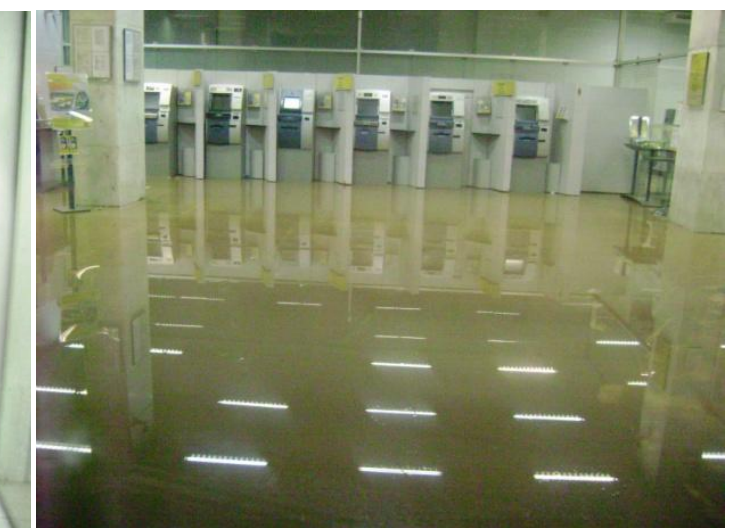

Figura 07 - inundação agência BB na Av. Mariana Amália. Ponto 4 Fonte: A voz da Vitoria, 2011. 


\section{4 - CONSIDERAÇÕES FINAIS}

O estudo aponta que em condições normais a BHRT,considerada em seus aspectos morfométricos anteriormente descritos,não deveria condicionar inundação.Esse fenômeno só ocorre conforme se vê nos resultados devido, sobretudo, à natureza da densidade de drenagem no trecho do médio curso da bacia onde se localiza o distrito sede de Vitória de Santo Antão, constatado não apenas pela existência de vários tributários, mas principalmente por alguns estarem confinados sob o asfaltoe pela grande impermeabilização do solo.

Ademais diante da ocorrência de eventos extremos oriundas de sistemas climáticos comuns à região, naturalmente há o aumento da pluviosidade local, e encontrando as características morfométricas da BHRT essas resultarameminundações, comoas registradasem 2005, 2010 e 2011. Nesse cenário ocorre um aumento gradativo do volume e velocidade da água que passa a apresentar maior competência no processo erosivo e de transporte de partícula e cascalho acima de sua capacidade normal.

Essa análise revelou ainda que os cenários possíveis para o futuro não serão nada agradáveis, já que nenhuma mudança rápida está em curso. Isso é constatadodevido às condições morfológicas da BHRT nesse trecho de médio curso, que possibilitará para a ocorrência de novos e recorrentes episódios de inundações.

\section{5 - REFERENCIAL BIBLIOGRÁFICO}

ALVES, K. M. A. da S.; CAVAlCANTI, L. C. de S.; NÓBREGA, R. S.Eventos Extremos e Risco de Inundação: Uma Análise do Comportamento Evolutivo dos Distúrbios Ondulatórios de Leste em Junho de 2010 sobre a Bacia do Rio Una - Pernambuco. Revista Geonorte. Edição Especial 2, V 1 - 2012

ANDRADE, S. L. de; FERREIRA, V. de O.; e SILVA, M. M.Elaboração de um mapa de risco de inundações da bacia hidrográfica do córrego São Pedro, área urbana de Uberlândia - MG Belo Horizonte, Caderno de Geografia, v.24, n.41, 2014

BRAGA, R. A. P. (Coord.) Gestão ambiental da bacia do Tapacurá: Plano de ação. UFPE/ CTG/DECIVIL/GRH; Recife: Ed. Universitária da UFPE, 2001.

CASTRO, A. L. C. Manual de desastres: desastres naturais. Brasília, Ministério da Integração Nacional, 2003. 174p.

DUARTE, C. C.Análise dos impactos das mudanças climáticas no escoamento superficial da Bacia Hidrográfica do rio Tapacurá - PE, a partir da utilização do modelo de balanço hídrico mensal semidistribuído. Dissertação de mestrado (Pós Graduação de Geografia), PPGEO, Recife, UFPE, 2009.

MACHADO, P. J.de O.e TORRES, F. T. P.Introdução à Hidrogeografia. São Paulo - SP - Editora CENGAGE Learning, 2012.

NAGHETTINI, M. C.Projeto Rio de Janeiro - Estudos de chuvas intensas no estado do Rio de Janeiro; Relatório Técnico; Companhia de Pesquisas de Recursos Minerais - CPRM, Belo Horizonte - 2000.

POPP, J. H.Geologia Geral. Grupo Editorial Nacional. LTC 6 ${ }^{\text {a }}$ Edição Rio de Janeiro, RJ 2010.

PORTO, R. de M.Hidráulica Básica. Escola de Engenharia de São Carlos - EESC São Paulo, Editora da Universidade de São Paulo - EDUSP, $4^{\mathrm{a}}$ Edição - 2006. 
PRESS, F.; SIEVER, R.; GROTZINGER, J.e JORDAN, T. H. Para Entender a Terra, $4^{\text {a }}$ Edição, Bookman editora, São Paulo - SP, 2008.

ROSS, J. L. S.Geografia do Brasil, Editora da Universidade de São Paulo, SP, 1996.

SILVA, D. G. da; MELO, R. F. T. de e CORRÊA, A. C. de B.A Influência da Densidade de Drenagem na interpretação da evolução Geomorfológica do complexo de Tanques do Município de Brejo da Madre de Deus - Pernambuco, Nordeste do Brasil. Revista de Geografia. Recife: UFPE - DCG/NAPA, v.26, n.3, jun/ago. 2009.

SILVERMAN, B. W.Density Estimation for Statistics and Data Analysis. New York: Chapman and Hall, 1986

TOMINAGA, L. K.; SANTORO, J.e AMARAL, R.Desastres Naturais: conhecer para prevenir, $1^{\text {a }}$ Edição, Instituto Geológico, Governo do Estado de São Paulo, 2009.

TUCCI, C. E. M. Gestão de Inundações urbanas Ministério das cidades secretaria nacional de saneamento ambiental, Porto Alegre. 2005.

VALERIANO, M. de M.TOPODATA: guia para utilização de dados geomorfológicos locais. Ministério de Ciências e Tecnologia - Instituto Nacional de Pesquisas Espaciais - INPE, São José dos Campos, SP, 2008.

VILELLA, S. M.; MATTOS, A.Hidrologia aplicada. São Paulo: McGraw-Hill. 1975. 